\title{
O FUTEBOL E A LITERATURA EM NELSON RODRIGUES E CARLOS DRUMMOND DE ANDRADE
} Angela Sivalli Ignatti ${ }^{\star}$

(iD) https://orcid.org/0000-0002-1253-2210

Como citar este artigo: IGNATTI, A. S. O futebol e a literatura em Nelson Rodrigues e Carlos Drummond de Andrade. Todas as Letras - Revista de Lingua e Literatura, São Paulo, v. 22, n. 3, p. 1-13, set./dez. 2020. DOI 10.5935/1980-6914/eLETLT 2012140

Submissão: janeiro de 2019. Aceite: abril de 2020.

Resumo: A partir das crônicas de futebol de Carlos Drummond de Andrade e Nelson Rodrigues, buscamos, neste artigo, analisar a presença do estilo lírico no primeiro autor e do dramático no segundo. No entanto, a análise desses estilos visa ao estabelecimento da relação entre as diferentes visões de mundo desses cronistas e o tema futebolístico. O futebol, enquanto elemento lúdico, é a janela que descortina para o leitor a visão de mundo dos autores, ambos conscientes da profunda influência desse jogo na cultura brasileira.

Palavras-chave: Futebol. Jogo. Lirismo. Drama. Teoria literária. 


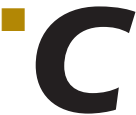

arlos Drummond de Andrade e Nelson Rodrigues dedicaram-se, na condição de jornalistas, à redação de crônicas esportivas dedicadas ao tema do futebol, o qual há mais de um século tem grande influência em nossa sociedade. A casualidade da crônica encontrou na popularidade do futebol um lugar para se contemplar a realidade sob diferentes aspectos. E o futebol abriu para esses escritores uma janela de múltiplas possibilidades de escrita literária. Como o jogo de futebol pode ser um tema tão propício para o lírico, o épico e o dramático é questão complexa. Compreender em camadas mais profundas dos estudos literários e culturais a influência do futebol na cultura brasileira, bem como observar as características líricas e dramáticas nas crônicas futebolísticas de dois grandes autores da literatura nacional são os objetivos deste texto.

Comecemos por falar do jogo. Johan Huizinga, em sua obra Homo Ludens, considerada um dos mais importantes estudos sobre a questão do jogo, introduz o tema de maneira bastante controversa. Para esse autor, o jogo antecede a cultura: "É-nos possivel afirmar com segurança que a civilização humana não acrescentou característica essencial alguma à ideia geral de jogo" (HUIZINGA, 2000 , p. 4). O autor observa a natureza e se refere aos animais que, quando jovens, brincam entre si, observa rituais de acasalamento e disputas por territórios em algumas espécies e relaciona esses comportamentos ao elemento lúdico.

Embora possamos observar a existência do jogo fora da cultura, nos animais e em comportamentos humanos primitivos, não seria correto analisar o elemento lúdico somente como algo necessário ao desenvolvimento fisiológico de determinadas espécies animais. Várias são as teorias que observam a questão unicamente por esse ângulo:

Umas definem as origens e os fundamentos do jogo como descarga da energia vital superabundante, outras como satisfação de um certo 'instinto de imitação' [...] Segundo uma teoria, o jogo constitui uma preparação do jovem para as tarefas sérias que mais tarde a vida dele exigirá, segundo outra trata-se de um exercício de autocontrole indispensável ao indivíduo. Outras vêm o princípio do jogo como um impulso inato para exercer uma certa faculdade, ou como desejo de dominar ou competir. Teorias há, ainda, que o consideram uma ab-reação, um escape para impulsos prejudiciais, um restaurador da energia despendida por uma atividade unilateral (HUIZINGA, 2000, p. 4).

$\mathrm{O}$ autor considera que todas essas teorias biológicas sobre a essência do jogo levam em consideração que o elemento lúdico tem sempre um propósito fora dele, ou seja, uma utilidade prática que se dá por meio do jogo. Porém, no curso de encontrar uma conceituação para o jogo que não esteja meramente ligada a questões extrínsecas ao fenômeno, o autor chega ao elemento considerado por ele como fundamental: o divertimento. A partir da observação da questão do divertimento, Huizinga considera que a existência dessa atividade não está ligada a qualquer grau determinado de civilização. De certa forma, se os animais são capazes de brincar é porque são capazes de desfrutar o divertimento.

Paradoxalmente a essa afirmação, os estudos de Johan Huizinga seguirão no sentido de estabelecer a enorme importância social do elemento lúdico, procurando compreender o jogo como um fator cultural da vida. Segundo ele, "As grandes atividades arquetípicas da sociedade humana são, desde o início, inteiramente marcadas pelo jogo" (HUIZINGA, 2000, p. 7). 
Podemos vislumbrar o jogo como elemento que compõe a linguagem. É a linguagem que nos permite distinguir as coisas, defini-las e constatá-las, sobretudo a linguagem nos permite "designar" e é por meio da designação que somos capazes de elevar as coisas ao domínio do imaginado. Na criação da fala e da linguagem, brincamos com a faculdade de designar e, dessa forma, o espírito humano salta constantemente entre a matéria e as coisas pensadas.

Por detrás de toda expressão abstrata se oculta uma metáfora, e toda metáfora é um jogo de palavras. Assim, ao dar expressão à vida, o homem cria um outro mundo, um mundo poético, ao lado da natureza (HUIZINGA, 2000, p. 4).

O mito e o culto são vistos por Huizinga como designações lúdicas. O mito, assim como a linguagem, é uma imaginação do mundo exterior, pois o homem primitivo procurava por meio dele dar conta da esfera dos fenômenos, atribuindo a estes um fundamento divino: "Em todas as caprichosas invenções da mitologia, há um espírito de fantasia que joga no extremo limite entre a brincadeira e seriedade" (HUIZINGA, 2000, p. 7).

Uma conceituação sobre o que é o jogo não é algo simples de apresentar, uma vez que a representação desse fenômeno na sociedade nos parece altamente intrincada. Possivelmente, a primeira característica que conceitua o jogo é o fato de ser livre e de certa maneira supérfluo. Segundo Huizinga (2000, p. 12), o jogo é relacionado à liberdade, já que não faz parte da "vida corrente", nem da vida "real". O jogo não é parte da realidade, é um intervalo dentro da vida corrente. Um jogo de futebol, por exemplo, é uma evasão do tempo que não é supérfluo, que não é livre.

Outras características são a limitação e o isolamento. O jogo é sempre praticado em um espaço delimitado e em um tempo determinado. Para Huizinga (2000, p. 13), uma característica interessante é que, embora o jogo esteja preso a uma delimitação de tempo, há nele uma capacidade de fixação imediata como fenômeno cultural; mesmo quando o jogo termina, ele é capaz de permanecer como uma "criação nova do espírito", "um tesouro a ser conservado pela memória".

A delimitação espacial do jogo é ainda mais notória. Todo jogo se processa e existe no interior de um campo previamente delimitado, de maneira material ou imaginária, deliberada ou espontânea. Os cultos religiosos possuem sempre um local determinado, e o jogo funciona da mesma maneira.

A arena, a mesa de jogo, o círculo mágico, o templo, o palco, a tela, o campo de tênis, o tribunal, etc., têm todos forma e função de terrenos de jogo, isto é, lugares proibidos, isolados, fechados, sagrados, em cujo interior se respeitam determinadas regras. Todos eles são mundos temporários dentro do mundo habitual, dedicados à prática de uma atividade especial (HUIZINGA, 2000, p. 13).

A ordem específica e absoluta que existe no domínio do jogo é outra de suas características. Dentro de seu tempo de duração, introduz uma ordem que não existe normalmente no tempo normal do mundo. Todo jogo possui, por mais rudimentar, algum tipo de regra, e a desobediência a isso estraga o jogo. Quando as crianças inventam um jogo, elas mesmas sabem determinar regras para aquilo.

A ideia das regras e da ordem presente no jogo em nada contradiz a ideia de liberdade. O jogo é um espaço livre dentro da ordem normal do mundo. Quem opta pelo jogo é livre. Em sua essência ele não é obrigatório, e o jogador tem a 
liberdade de jogar ou não. Porém, uma vez dentro do jogo, precisa respeitar a ordem interna.

"O jogo é tenso", afirma Huizinga (2000, p. 13). Quando uma criança joga bola ou monta um quebra-cabeça, quando um gatinho tenta dominar um novelo de lã ou um cachorrinho corre atrás de uma roda, todos eles buscam alguma coisa que, de certa maneira, é um desafio para eles conseguirem. A tensão significa justamente a incerteza, o acaso. Nos jogos de azar ou nas competições esportivas, a tensão chega a niveis extremos.

É importante acrescentar ainda a questão das agremiações. Devido ao fato de o jogo separar as pessoas numa espécie de mundo temporário, quando se trata de jogos em grupo, as pessoas tendem a se sentir melhor "separadamente juntas". Porém, o mais importante, talvez, quando falamos de clubes ou torcidas, é pensar no que realmente significa ganhar um jogo. Ganhar um jogo significa conferir ao vencedor superioridade, estima, honrarias. Por meio da lógica do lúdico, tudo isso é automaticamente transferido para o grupo ao qual o ganhador pertence. O êxito obtido no jogo pertence tanto ao indivíduo quanto ao grupo que torce por ele. As pessoas que assistem a jogos tendem a se enxergar no lugar dos que estão jogando. O jogo está abaixo do nivel da seriedade, mas seria uma atividade desenvolvida seriamente.

O antropólogo Roberto DaMatta, em artigo publicado no Dossiê Futebol, na Revista USP, comenta um ditado popular em que se diz que no Brasil só existem três coisas sérias: a cachaça, o jogo de bicho e o futebol. Ao tentar explicar essas três "unanimidades nacionais", DaMatta (1994, p. 11) destaca o futebol:

[...] dentre essas instituições, o futebol é certamente a mais moderna e a que chegou ao Brasil por meio de um bem documentado processo de difusão cultural. De fato, enquanto a cachaça e ojogo de bicho atendem a motivações que se perdem na história, o futebol foi introduzido no Brasil sob o signo do novo, pois, mais do que um simples "jogo", estava na lista das coisas moderníssimas: era um "esporte". Ou seja, uma atividade destinada a redimir e modernizar o corpo pelo exercício fisico e pela competição, dando-lhe a higidez necessária a sua sobrevivência num admirável mundo novo - esse universo governado pelo mercado, pelo individualismo e pela industrialização.

Apesar de sua grande penetração popular, o futebol chegou ao Brasil para ser o esporte da elite. Charles Miller é o célebre brasileiro de origem inglesa que, após terminar seus estudos na Europa, voltou a São Paulo, em 1894, trazendo na mala uma bola de football. Miller tornou-se um verdadeiro missionário para a divulgação do esporte britânico no Sudeste brasileiro. São Paulo e Rio de Janeiro tinham uma comunidade britânica considerável, composta, sobretudo, por engenheiros e altos funcionários da São Paulo Railway, empresa que fazia a expansão ferroviária no país, funcionários da Companhia de Gás, também inglesa, do Banco de Londres e de outras empresas anglo-saxônicas.

Os primeiros seguidores brasileiros desse esporte vinham dessas comunidades estrangeiras ou eram jovens de camadas sociais superiores recém-chegados às cidades grandes para estudar. A primeira equipe de futebol essencialmente brasileira era formada pelos alunos do Mackenzie College, de São Paulo, que mais tarde fundaram o Clube Mackenzie. Logo, outros jovens europeus e filhos de imigrantes abastados começaram a formar algumas agremiações, como o Clube Germânia (atual Clube Pinheiros). 
O futebol era visto pela elite brasileira como uma maneira de manter o corpo em forma, ajudando no desempenho intelectual. A disciplina dos treinos e as regras a serem respeitadas dentro do campo, entre elas a do fair play, ou jogo limpo, seriam essenciais ao sucesso das futuras práticas executivas dos novos empreendedores brasileiros. Em 1905, já existiam mais de 250 clubes ou agremiações futebolísticas.

Contudo, os meninos dos subúrbios e de classes baixas começaram, já no início do século $\mathrm{XX}$, a assistir as partidas entre os jovens ricos dos colleges e dos clubs. Nas "gerais" - como eram e como ainda são chamados os locais na plateia destinados ao povo em geral -, começaram a aparecer jovens que não tinham acesso ao estudo ou ao trabalho e, assim, não tinham o que fazer. Foram exatamente esses meninos, os quais entenderam rapidamente as regras do jogo de futebol, seu funcionamento e suas táticas, que começaram a formar times de "pelada".

A simplicidade das regras do futebol, a falta da necessidade de equipamento específico para sua prática e o fato de quase qualquer garoto poder jogá-lo aliaram-se ao momento histórico que o Brasil vivia. As metrópoles começando a se formar, uma grande concentração populacional em cidades como Rio de Janeiro e São Paulo, que foram o berço do futebol de elite, a formação de uma massa de jovens sem possibilidade de estudo ou trabalho levaram a uma rápida disseminação do futebol na região Sudeste do país. Mas uma nova safra de participantes começou a surgir - eles não pertenciam às elites, nem ao grupo de jovens ociosos do povo: eram os trabalhadores das fábricas.

Começaram então a surgir times das fábricas e times de várzea em subúrbios. Os campeonatos passaram a incluir times fabris, juntando-os aos tradicionais clubes de elite, como Fluminense, Pinheiros, Mackenzie etc. Os times compostos por pessoas de camadas inferiores da sociedade eram amplamente discriminados pelos outros. Mas o caráter democratizante do futebol foi o que uniu essas equipes. Não porque os ricos aceitassem os pobres. Simplesmente porque os pobres jogavam tão bem, ou melhor, quanto os ricos, e o nível técnico e competitivo dos campeonatos começou a se elevar.

Nessa mistura entre membros da elite, jovens pobres e operários, passa a existir no Brasil um futebol de características diferentes do jogo de bola dos bretões. Começa a surgir o "jeitinho brasileiro" de jogar. O jogador pobre aprendia rapidamente o esquema do esporte inglês, mas somava a ele a malandragem das ruas, as habilidades da capoeira, do samba, das brigas. Os times de várzea eram verdadeiras escolas desse futebol mais solto, que trabalhava com as regras, mas criava diferentes formas de jogar.

No final dos anos 1920, houve a chamada Crise do Amadorismo, fruto da luta pela profissionalização desse esporte. O movimento teve como um de seus maiores incentivadores o jornalista Mario Rodrigues Filho, irmão de Nelson Rodrigues, e culminou na profissionalização do esporte no Brasil, em 1933.

Ao contrário do que se pensa, a profissionalização do esporte inglês, sob alguns aspectos, não descaracterizou a essência do jogo. O fato de, atualmente, alguns jogadores ganharem milhões para jogar no Brasil ou no exterior e de dirigentes esportivos estarem envolvidos em grandes esquemas de corrupção que se misturam a contravenções politicas não anula as características lúdicas desse esporte, principalmente pelo fato de que o jogo não abrange apenas os que jogam - inclui também os que assistem a ele, os seus torcedores. 
De acordo com o historiador brasileiro Nicolau Sevcenko (1994, p. 35-36), a torcida é um fator básico do jogo. O sucesso do futebol no Brasil e no mundo, na opinião desse autor, está em grande parte relacionado ao surgimento do enorme número de torcedores. Para Sevcenko, as torcidas surgem um tanto pelas características do jogo de futebol, outro tanto por questões geográficas. Não acidentalmente, tanto no Brasil como na Europa o esporte inglês se desenvolveu em cidades grandes, metrópoles em potencial. A população desses lugares é composta, sobretudo, por migrantes e imigrantes que não possuem raízes culturais ali; precisam, portanto, criar laços e bases que substituam suas comunidades, famílias e sociedades anteriores:

Na sua busca de novos traços de identidade e de solidariedade coletiva, de novas bases emocionais de coesão que substituíssem as comunidades e os laços de parentesco que cada um deixou ao emigrar, essas pessoas se veem atraidas, dragadas para a paixão futebolística que irmana estranhos, os faz comungarem ideias, objetivos e sonhos, consolida gigantescas famílias vestindo as mesmas cores. O futebol se presta maravilhosamente para consolidar vínculos de identidade plenos de carga afetiva (SEVCENKO, 1994, p. 35).

Diante da formação das grandes massas de torcedores e da dimensão social que tomou no Brasil, o futebol é visto por alguns estudiosos como um elemento alienador. Não podemos negar que um esporte como o futebol não seja utilizado por grupos de pressão como os políticos ou a mídia para que tal atividade lúdica trabalhe em favor de seus interesses.

É bastante conhecido o uso que os governantes do periodo da ditadura militar vivida aqui fizeram do futebol. A participação do Brasil na Copa do Mundo de 1970, no México, representou, segundo o sociólogo Waldenyr Caldas (1994, p. 47), um exemplo dessa manipulação popular. A conquista do tricampeonato mundial em 1970 coincidiu com o auge do autoritarismo militar. Nos "anos de chumbo", prevaleceu o rígido controle social empreendido pela ditadura para a manutenção do estado de coisas em favor das elites socioeconômicas. Assim, revoltas populares, efervescências politicas ou sociais eram mantidas sob controle com a força dos militares por meio de constantes prisões, torturas e execuções de jornalistas, professores, intelectuais, estudantes.

Quanto às massas populares, estas eram mantidas sob controle, em parte por meio dos grandes campeonatos de futebol incentivados pelo Estado. O número de times nas regiões Norte e Nordeste cresceu vertiginosamente com o apoio dos militares. A maioria dessas equipes não sobreviveu ao fim desse regime político. O futebol era um elemento perfeito para manter a população à parte de problemas de ordem social ou econômica. O próprio Pelé foi visto, durante algum tempo, como um apoiador do regime totalitarista no país, enquanto atuava como jogador. Esse craque do futebol teria servido, algumas vezes, como símbolo na propaganda dos militares. O professor Waldenyr Caldas cita uma entrevista concedida por Pelé ao jornal La Opinion, de Montevidéu, em 1972.

Quando perguntado pela jornalista Amália Barran sobre a ditadura militar no Brasil, Pelé respondeu: "Não há ditadura no Brasil. O Brasil é um país liberal, uma terra de felicidade, somos um povo livre. Nossos dirigentes sabem o que é melhor para nós e nos governam com tolerância e patriotismo" (CALDAS, 1994, p. 47). 
No entanto, Caldas discorda veementemente de que o futebol seja um esporte alienante, que desvie as massas de questões mais importantes como a má distribuição de renda, as injustiças sociais, a corrupção, entre outras coisas. Ao contrário, ele considera o futebol como um esporte democratizante. Se não fosse o futebol, poderia ter sido outro esporte, outra atividade. A questão é que o jogo inglês já era uma mania nacional antes de o Estado descobrir sua aplicação pragmática. Referindo-se à vitória na Copa de 1970, o sociólogo diz o seguinte:

Se nessa época determinados segmentos da sociedade brasileira se distanciam de seus problemas mais prementes, a culpa não foi do futebol nem do tricampeonato. A causa está no estado de terror imposto aos brasileiros, cerceados em quase todos os seus direitos, entre eles o direito à informação e à participação política. [...] Assim como o Estado autoritário pode usar o futebol para corroborar ainda mais o seu poder, no Estado democrático esse mesmo futebol pode dar verdadeiras demonstrações de amor à liberdade e à democracia (CALDAS, 1994, p. 47).

As afirmações de Waldenyr Caldas parecem ir ao encontro do processo histórico da disseminação desse esporte no país, que cresceu muito mais pelo seu caráter democrático e de inclusão social do que por imposição desse ou daquele grupo de pressão. Assim como Huizinga (2000) vê a questão do jogo, Roberto DaMatta (1994) entende o futebol como uma estrutura autônoma dentro da sociedade, que se insere na cultura, modificando-a, mas que é independente dela.

Na década de 1980, ocorreu um movimento notório, a chamada "democracia corintiana". Tratou-se de uma mobilização que, com o final do regime ditatorial, começou a pregar a desvinculação política do time e a modernização no trato com a relação profissional dos jogadores. Essa mobilização foi liderada pelo ex-vice-presidente do Corinthians Adilson Monteiro Alves e pelos jogadores Sócrates e Casagrande, entre outros. O jornalista Juca Kfouri também contribuiu muito para a nova ordem do futebol democratizante, pois, junto com Adilson Monteiro e Sócrates, redigiu, em 1983, um documento intitulado "Profissionalismo no futebol e a estrutura atual", que teve grande valor no sentido de trazer a público a precariedade da estrutura que submetia os jogadores profissionais à organização autoritária dos clubes.

Contudo, para o torcedor, pouco disso interessa. Quando começa o jogo, seja no Maracanã, seja no Morumbi ou no campo de várzea, acontece o desligamento do tempo sério da vida e dá-se início, paradoxalmente, a um ritual praticado com extrema seriedade, que será visto por nossos dois cronistas, Carlos Drummond de Andrade e Nelson Rodrigues, como um espetáculo lírico ou dramático. Drummond e Nelson são capazes de usar suas habilidades artísticas para, fora das águas da poesia e do teatro, e dentro do terreno do jogo, externarem o lirismo e a dramaticidade que fazem parte de suas visões de mundo.

Drummond usa recursos em suas crônicas sobre futebol que evidenciam uma postura lírica de ver o mundo - uma forma que denuncia um olhar sensível, amargurado e crítico em relação à sociedade. Os textos sobre o esporte desse poeta mostram um sujeito lírico de ampla consciência da importância do futebol na vida das pessoas, do país e em sua própria vida. O futebol, nas crônicas de Carlos Drummond de Andrade, é uma forma de expressar sua inquietação com o mundo porque o cronista é capaz de absorver para seus textos os elementos líricos presentes nas partidas, vitórias e derrotas desse jogo de bola. 
Perdendo, após o emocionalismo das lágrimas, readquirimos (ou adquirimos, na maioria das cabeças) o senso da moderação, do real contraditório, mas rico de possibilidades, a verdadeira dimensão da vida. Não somos invencíveis. Também não somos uns pobres-diabos que jamais atingirão a grandeza, este valor tão relativo, com tendência a evaporar-se. Eu gostaria de passar a mão na cabeça do Telê Santana e de seus jogadores, reservas e reservas de reservas, como Roberto Dinamite, o viajante não utilizado, e dizer-lhes, com esse gesto, o que em palavras seria enfático e meio bobo. Mas o gesto vale por tudo, e bem o compreendemos em sua doçura solidária. Ora, o Telê! Ora, os atletas! Ora, a sorte! A Copa do Mundo de 82 acabou para nós, mas o mundo não acabou. Nem o Brasil com suas dores e bens. E há um lindo sol lá fora, o sol de nós todos (ANDRADE, 2002, p. 23).

Em Nelson Rodrigues, encontramos uma postura muito diferente em relação à maneira de ver a vida pelo mundo do futebol. Nelson Rodrigues revela-se um fanático pelo esporte. Em suas crônicas, o mundo gira em torno de uma sucessão de fatos extremamente intensos, repletos de tensão dramática. Os jogos e campeonatos são descritos por esse cronista com a ênfase que revela extremos de alegria, ódio, tristeza. Por meio do jogo, Nelson é capaz de revelar um estilo que prima pelo que leva às últimas consequências, que se guia por emoções que geram o estranhamento no leitor.

E como foi empolgante o coração de Vavá! Há quem diga, inclusive patrícios nossos: - “O Brasil não tem caráter, o Brasil não tem moral!”. Mas olhem Vavá. Não tem medo de ninguém, medo de nada. Se for preciso, ele dará a cara para o inimigo chutar. É, mal comparando, um Tartarin desgrenhado, que pegasse, à unha, leões de verdade. Ontem, machucou-se, e por quê? Porque entregou a canela para o inimigo fraturar. Foi a canela, como poderia ter sido a base do crânio. Sabe-se que os franceses, furiosos com o deslumbrante baile do Brasil, baixaram o sarrafo. Caçado a pontapés, na área e fora, perseguido quase a pauladas, eis que Vavá sobrevivia ao massacre. Ele e os companheiros. Ora, é desse peito largo e inexpugnável que o escrete brasileiro sempre precisou (RODRIGUES, 1994, p. 127).

Emil Staiger, grande estudioso da teoria literária, considera que a questão da divisão de características em lírico, épico e dramático vai muito além de características de produção artístico-literária, e esses termos só existem porque se enquadram nos domínios do emocional e do lógico, constituindo a essência do homem: "Os conceitos de lírico, épico e dramático são termos da Ciência da Literatura para as virtualidades fundamentais da existência humana" (STAIGER, 1969, p. 130, grifo nosso).

De certo modo, podemos pensar que essa tridivisão, a qual se relaciona com a capacidade funcional da linguagem e do pensamento humano, se fundamenta nos domínios emocionais e lógicos da existência humana, como três diferentes formas de um autor ver sua existência no mundo. Ou seja, é possível afirmar que elementos dramáticos nas crônicas de Nelson Rodrigues ou líricos nas crônicas de Drummond subjazem a uma cosmovisão, lírica em Drummond e dramática em Nelson.

As pessoas possuem várias formas de interpretar e perceber o mundo que as cerca; porém, cada um possui uma forma dominante de analisar fatos ou situações. Com relação a isso, Staiger (1969) usa como exemplo um barranco de terra 
que, visto por um agricultor, é observado como terra improdutiva, mas por um militar, pode ser apreciado com vistas a táticas de proteção, de campo; um pintor verá a terra como uma paisagem composta de diferentes matizes e nuances.

Assim, na obra literária, não é aconselhável uma rotulação rígida, pois o texto pode abarcar múltiplas visões. No entanto, um estilo ou uma mundivisão será predominante, e esse fato poderá dar à composição características predominantemente líricas, épicas ou dramáticas.

As diferenças decorrentes dos mundos são diferenças estilisticas, de tal modo que podemos em análises estéticas usar sem escrúpulos "mundo" e "estilo" como sinônimos. Um verdadeiro poeta tem estilo próprio, isto é, seu próprio mundo (STAIGER, 1969, p. 140).

Para entendermos melhor essa mundividência, precisamos estabelecer mais claramente o que é o elemento lírico que a constitui. Já sabemos que o lirismo não pode ser aqui compreendido sob uma ótica normativa. Podemos falar de lírico, mas não da lírica como gênero fechado. O lirismo, de forma geral, é uma maneira de expressão particular, constituída por relações estabelecidas entre som, sentido, ritmo e imagens. Tais relações são comandadas por uma visão subjetiva de um sujeito lírico.

Dessa maneira, um texto de características líricas é aquele pontuado pelos elementos de sonoridade, sentido, ritmo e imagens, coordenados por essa visão subjetiva do "sujeito lírico", que se relacionam, na maioria das vezes, por meio de uma tensão lírica. A estudiosa da teoria literária Salete de Almeida Cara (1998, p. 58) afirma que na expressão lírica há uma espécie de tensão que luta contra qualquer intencionalidade de explicar objetivamente emoções ou sentimentos.

Carlos Drummond de Andrade, na condição do sujeito lírico de suas crônicas, consegue, mediante construções metafóricas, essa relação de não interpretação total de seu texto. O assunto futebol, que por muitos poderia ser tratado como questão objetiva, passa ao nível subjetivo, nebuloso, apresentando uma sensibilidade particular do autor em relação ao tema.

O que aponta para uma cosmovisão lírica é que Drummond lança tais questões de modo que elas estejam circundadas pela vaguidão da metáfora, pela tensão rítmica, a qual leva o leitor a vibrar na mesma disposição anímica do sujeito lírico. Essa disposição anímica é solitária, é a demonstração de um "sentir" o mundo e não de um simplesmente "observar" o mundo.

A visão de Drummond acerca dos acontecimentos da realidade concreta refere-se a uma visão sensorial dos acontecimentos que o inquietam, e não a uma visão narrativa contemplativa dessas problemáticas. Staiger (1969) ajuda-nos a entender melhor essa cosmovisão lírica ao afirmar que a disposição anímica do sujeito lírico nada tem a ver com o que está dentro dele, e sim com a sua forma de sentir o que está fora dele. De maneira que o sujeito lírico não quer interpretar a realidade que o cerca, ele simplesmente a sente:

Originalmente, porém, a disposição [lírica] não é nada que exista "dentro" de nós; e sim na disposição estamos maravilhosamente "fora” de nós. A disposição apreende a realidade diretamente, melhor que qualquer intuição ou qualquer esforço de compreensão (STAIGER, 1969, p. 59).

Nos trechos a seguir, da crônica "Mané e o sonho", podemos identificar, em sintese, o que expomos: 
$1^{\circ}$. A necessidade brasileira de esquecer os problemas agudos do país, dificeis de encarar, ou pelo menos de suavizá-los com uma cota de despreocupação e alegria, fez com que o futebol se tornasse a felicidade do povo. Pobres e ricos param de pensar para se encantar com ele. E os jogadores convertem-se numa espécie de irmãos da gente, que detestamos ou amamos na medida que nos frustram ou nos proporcionam o prazer de um espetáculo de 90 minutos, prolongado indefinidamente nas conversas e mesmo na solidão da lembrança (ANDRADE, 2002, p. 217).

$2^{\circ}$. Mané Garrincha foi um desses ídolos providenciais com que o acaso veio ao encontro de massas populares e até dos figurões responsáveis periódicos pela sorte do Brasil, ofertando-lhes o jogador que contrariava todos os princípios sacramentais do jogo, e que no entanto alcançava os mais deliciosos resultados. Não seria mesmo uma indicação de que o país, despreparado para o destino glorioso que ambicionamos, também conseguiria vencer suas limitações e deficiências e chegar ao ponto de grandeza que nos daria individualmente o maior orgulho pela extinção de antigos complexos nacionais? Interrogação que podia muito bem instalar-se no subterrâneo do espírito de cada patrício inquieto $e$ insatisfeito consigo mesmo, e mais ainda com o geral da vida (ANDRADE, 2002, p. 217).

No primeiro parágrafo, percebemos a sensibilidade do autor para questões sociais do país. De maneira filosófica, vai apresentando o futebol como um bálsamo capaz de suavizar as dificuldades do povo. Nessa apresentação amargurada e reflexiva sobre a importância do jogo na vida do brasileiro não há preocupação com uma narrativa que avance em direção ao futuro. O autor permanece refletindo, no presente, o que a questão do futebol significa para o país. Inclusive, o próprio autor se insere nessa massa de pessoas que vê no futebol um acalanto para as dificuldades da vida.

O estudioso alemão Wolfgang Kayser (1985, p. 407), ao se debruçar sobre o gênero dramático, afirma tratar-se de uma forma de apresentação de uma das já mencionadas atitudes do pensamento humano, a dramática: "O dramático é, ao lado do lírico e do épico, a terceira concepção do mundo que reside na própria lingua". Esse autor considera que a partir do dramático, concebido como forma de interpretar a realidade, é que se pode chegar ao gênero dramático e deste para o teatral, culminando, então, na representação de palco.

Portanto, uma cosmovisão dramática é facilmente identificada no gênero dramático porque o segundo pressupõe a primeira; já a primeira não tem sua existência vinculada ao segundo. Muitas vezes, equivocadamente, o conteúdo é reconhecido pelo seu continente, pelo gênero que o comporta, que lhe serve tão bem como fôrma. Afinal, o drama, em sua acepção clássica, de representação teatral, é o espaço fértil para a exposição do drama entendido aqui como concepção de mundo. A intensa atividade jornalística de Nelson Rodrigues já comportava intensamente o dramático, porém revestido pela fôrma de outros gêneros, tais como a notícia e a crônica.

Analisando textos de Nelson, podemos observar construções que trabalham no sentido de tornar tenso algo que, às vezes, poderia ser dito de maneira simples, sob um olhar contemplativo. Mas a contemplação não é uma atitude do dramático; pelo contrário, este se faz notar pela inquietação do discurso. Wolfgang Kayser (1985, p. 408) comenta que a atitude dramática trabalha com um olhar inquietante sobre a vida: 
Onde quer que o mundo se torne dramático, cessa aquela calma contemplação, aquele largo distanciamento, aquele amor por cada ponto isolado na variegada plenitude da existência, que são, na verdade, características da atitude épica.

Kayser considera que a mundividência dramática acaba se encaixando tão bem no conceito de representação teatral justamente porque a transferência da inquietação e da violência do discurso dramático é bem transmitida pela encenação. Esse fato não pressupõe que a cosmovisão dramática só possa ser exposta pela encenação em palco. Em Emil Staiger (1969, p. 120), temos a questão apresentada de forma mais clara:

Teatral e dramático não significam, portanto, o mesmo. [...] Seria então aconselhável explicar essa relação dizendo que o dramático não tem que ser compreendido a partir de sua representação no palco, e sim que a instituição histórica do palco decorre da essência do estilo dramático? Um enfoque fenomenológico só permite essa interpretação.

É a partir desse ponto que Staiger vai nos guiando sobre o que seria o estilo dramático. O pathos (sofrimento) e o problema são elementos do estilo dramático. São as duas atitudes que geram a violência do discurso, que questionam e interpelam o leitor e que ajudam significativamente na construção da tensão. Mas, mais importante, o pathos e o problema levam a narrativa dramática adiante, gerando um desenrolar de fatos ou situações em direção ao futuro.

Nas crônicas de futebol de Nelson, vemos a interação do texto com o leitor sendo feita por vários elementos; entre eles destacam-se o uso do discurso direto com interrogações e o uso do vocativo que "chama" o leitor para as ações patéticas. O fato de Nelson usar os discursos diretos, as interrogações e o vocativo aponta para o que disse Kayser (1985, p. 408) a respeito do dramático: "À força de ser constantemente interpelado, o respectivo eu vê-se constrangido a resoluções e portanto a juízos". Dialogar com o público leva escritor e leitor ao questionamento e ao julgamento sobre as questões que são colocadas pelas vozes do texto, seja pelo cronista, seja pelos personagens que ele cria.

$1^{\circ}$. Amigos, vocês se lembram da vergonha de 50. Foi uma humilhação pior que a de Canudos. O Uruguaio Obdulio ganhou de nosso escrete no grito e no dedo na cara. Não me venha dizer que o escrete é apenas um time. Não. Se uma equipe entra em campo com o nome Brasil e tendo por fundo musical o hino pátrio - é como se fosse a pátria em calções e chuteiras, a dar botinadas e a receber botinadas (RODRIGUES, 1993, p. 102).

$2^{\circ}$. Pois bem. Depois da experiência bíblica de 50, passamos a rosnar, por todas as esquinas e por todos os botecos do continente, o seguinte juizo final sobre nós: - "O brasileiro é bom de bola, mas frouxo como homem". É o que diziam, sim, de nós, com feroz sarcasmo, os craques da Argentina e os craques do Uruguai. Até que vem aquele famoso Campeonato Sul Americano de 1959. Há o jogo Brasil X Uruguai. E, de repente, estoura um sururu monstruoso. Brigaram até as cadeiras (RODRIGUES, 1993, p. 102).

$3^{\circ}$. Foi uma página de Walter Scott. O próprio Chinesinho, com seu tamanho de anão de Velásquez, levou e deu bordoada. Lindo, lindo foi quando Didi tomou distância, correu e saltou. Por um momento ele se tornou leve, elástico, acrobático. E enfiou duas chuteiras em flor na cara do inimigo. Quando parou a guerra e continuou o jogo, demos um banho de bola (RODRIGUES, 1993, p. 102). 
Para finalizar este texto, retorno a Huizinga (2000, p. 159), que considera importante levantar a questão de que nem sempre existe uma intenção lúdica na criação poética: "O fato de a poesia, no sentido amplo da poiesis grega, sempre se encontrar dentro da esfera do jogo, não significa que seu caráter essencialmente lúdico seja sempre conscientemente mantido". Por serem intrinsecamente relacionadas ao jogo, as atitudes líricas e dramáticas inserem-se nesse universo sempre que forem utilizadas dentro das características fundamentais aqui apresentadas. Por isso é que esse autor não aceita a teoria de alguns estudiosos que entendem os recursos de ritmo, tensão, metáfora, hipérbole, entre outros, segundo critérios estéticos. Por seus estudos, que vão buscar fundamentos nas civilizações da Antiguidade, Huizinga (2000, p. 134) considera que a produção poética precisa ser compreendida sob a ótica de outras doutrinas:

A primeira coisa que é preciso fazer para ter acesso à compreensão é rejeitar a ideia de que a poesia possui apenas uma função estética ou só pode ser aplicada através da estética. Em qualquer civilização viva e florescente, sobretudo nas culturas arcaicas, a poesia desempenha uma função social e litúrgica ao mesmo tempo.

Se futebol, lirismo e drama são elementos vindos da mesma origem, podemos então afirmar que, em última análise, os cronistas Drummond e Nelson possuem uma visão lúdica do mundo?

No caso de Carlos Drummond de Andrade e de Nelson Rodrigues, concluímos que tanto do ponto de vista estilístico quanto do conteúdo de suas crônicas, o jogo das palavras existe no texto cumprindo a função lúdica da poiesis. Se a função poética da linguagem é um jogo, o futebol também é. Dessa maneira, nossos cronistas uniram esses dois elementos de origem lúdica, consciente ou inconscientemente imprimindo suas marcas líricas e dramáticas, e criaram suas crônicas de futebol.

\section{Football and literature in Nelson Rodrigues and Carlos Drummond DE ANDRADE}

Abstract: Using the chronicles of Carlos Drummond de Andrade and Nelson Rodrigues as starting points, we sought in this work to analyse the presence of the lyric style in the first author and the dramatic in the latter. However, the analysis of such style aims to establish the relationship the two authors had of the world and the theme of football. Football, as a game-like element, plays the role of a window which opens up to the reader the vision both writers had of the world. The writers are aware of the profound influence of such game in the Brazilian culture.

Keywords: Football. Game. Lyricism. Drama. Literary theory.

\section{REFERÊNCIAS}

ANDRADE, C. D. Quando é dia de futebol. Rio de Janeiro: Record, 2002.

CALDAS, W. Aspectos sociopolíticos do futebol brasileiro. Revista USP, São Paulo, n. 22, p. 40-49, jun./ago. 1994. 
CARA, S. de A. A poesia lírica. 4. ed. São Paulo: Ática, 1998.

DAMATTA, R. Antropologia do óbvio: notas em torno do significado social do futebol brasileiro. Revista USP, São Paulo, n. 22, p. 10-17, jun./ago. 1994.

HUIZINGA, J. Homo Ludens. São Paulo: Perspectiva, 2000.

KAYSER, W. Análise e interpretação da obra literária. 7. ed. Coimbra: Armênio Amado Ed., 1985.

RODRIGUES, N. À sombra das chuteiras imortais. Organização Ruy Castro. São Paulo: Companhia das Letras, 1993.

RODRIGUES, N. A pátria de chuteiras. Organização Ruy Castro. São Paulo: Companhia das Letras, 1994.

SEVCENKO, N. Futebol, metrópoles e desatinos. Revista USP, São Paulo, n. 22, p. 30-37, jun./ago. 1994.

STAIGER, E. Conceitos fundamentais da poética. Rio de Janeiro: Edições Tempo Brasileiro, 1969. 